Hamlin, R. G., Kang. H-H, Chai, D.S., \& Kim, S. (2022), "Deducing an emergent South Korean

behavioural taxonomy of perceived managerial and leadership effectiveness", European Journal of Training and

Development, Vol. 46 No. 1/2, pp. 41-69. https://doi.org/10.1108/EJTD-04-2020-0069

\title{
Deducing an Emergent South Korean Behavioural Taxonomy of Perceived Managerial and Leadership Effectiveness
}

\begin{abstract}
Purpose

To identify people's perceptions of what behaviourally differentiates effective managers from ineffective managers within a South Korean (SK) public sector organization, and the extent to which the findings are similar or different to those of an equivalent previous study in the SK private sector

\section{Design/Methodology/Approach}

Adopting the 'pragmatic approach' and assuming a post-positivist ontology and constructivistinterpretivist epistemology, examples of 'effective' and 'ineffective' managerial behaviour were collected from managers and non-managerial employees in a SK central government Ministry using the critical incident technique. The collected critical incidents were coded, classified, and reduced to a smaller number of behavioural categories. These were then compared against equivalent findings from a previous SK private sector replication study using open, axial, and selective coding to identify generic behavioral criteria (GBCs).
\end{abstract}

\section{Findings}

High degrees of convergence point toward the emergence of a 'two-factor' SK behavioural taxonomy of perceived managerial and leadership effectiveness comprised of positive $(n=11)$ and negative $(n=4)$ GBCs of effective and ineffective managerial behaviour.

\section{Practical Implications}

The GBCs constituting the deduced SK behavioural taxonomy could be used by HRD practitioners to critically evaluate the efficacy of extant management and leadership development (MLD) programmes, or to inform/shape the creation of new MLD programmes. Additionally, they could be used by other HR professionals to critically evaluate the relevance and efficacy of the assessment criteria used for existing management selection, 360-degree feedback, and formal performance appraisal systems.

\section{Originality/Value}

The emergence of a SK behavioural taxonomy through Type 3 (emic-as-emic) and Type 4 (emic-andetic) indigenous research is a rare example of Eastern mid-range theory development.

Keywords: South Korea, public sector managers, private sector managers, perceived behavioural effectiveness, generic behavioural criteria, cross-case/cross-sector comparative analysis 


\section{Introduction}

Over the past two decades there have been numerous calls from Asia-Pacific countries for contextualizing organization research and indigenous emic management-related research. For example, Tsui (2004), "recognizing that existing [Western] models of management in the literature may not be valid in other societal contexts" (p. 491) argues that to expand global management knowledge "there is enormous need for high quality single country indigenous research" (p. 501). This view is echoed by Lyles (2009) who suggests there is an urgent need for indigenous research to develop locally derived theories due to disillusion [in Asia-Pacific countries] with the universalistic claim of Western theories. Similarly, Li, Zhou and Sekiguchi (2014) claim that because most extant management related theories are built upon the cultural values and empirical evidence in the West, it is imperative to conduct indigenous research to likely revise and modify, potentially supplement and enrich, or even supersede and replace Western theories. In response to these calls, our empirical qualitative emic replication study of effective and ineffective managerial behaviour within the South Korean (SK) public sector, and subsequent comparative analysis of its findings against those resulting from a previous equivalent study within the SK private sector (Chai, Jeong, Kim, Kim, and Hamlin, 2016; Hamlin, Kim, Chai, Kim, and Jeong, 2016) aims primarily to generate empirical evidence of indigenous concepts from which an Eastern model or mid-range theory might emerge.

According to Rainey and Chun (2007), various major organization theorists have proclaimed that public and private management show more similarities than differences, and despite claims about the importance of 'difference' between public and private management the prevailing consensus among scholars and experts hold that the distinction is not worth much. However, this view is open to question bearing in mind Orazi, Turrini, and Valotti’s, (2013) 
more recent claim that $21^{\text {st }}$ century administrative leaders in the public sector behave differently from their counterparts in the business world; and Getha Taylor et al.'s (2011) assertion that public leadership is becoming a distinctive and autonomous domain in the field of public administration/public management which, they argue, needs to be studied separately from general leadership. Furthermore, as Vogel and Masal (2015) suggest, the increasingly complex and ambiguous world of the $21^{\text {st }}$ century has placed new challenges and pressures on public sector organizations. These challenges, as various other writers assert, call for less reliance on the types of hierarchical authority exercised in the $20^{\text {th }}$ century, and more on: i) public managers exercising the skills of negotiation, inter-organizational diplomacy, and relationship building in managing upwards, downwards and outwards (Head, 2010; O’Toole, Meier and NicholsonCrotty, 2005); ii) effective top-down policy leadership from organizational leaders; iii) effective middle-out administrative leadership from operational public managers at the senior, middle and first line levels of management (Wallis and McLoughlin, 2007); and iv) the building of leadership capabilities at all levels in public sector organizations whereby managers have the cognitive skills necessary to improve operational delivery further in an environment of fiscal constraint, and to develop the skills to lead agile, highly productive teams (Leslie and Canwell, 2010). Thus, current debate on whether 'difference' between public and private management is significantly worth much remains inconclusive, and this suggests more research on the issue is warranted.

These contemporary views on 'difference' support Van Wart's $(2003 ; 2013)$ calls for public management researchers to: (i) identify the specific managerial behaviours perceived positively (or negatively) by employees which are thus likely to motivate (or de-motivate) them in the continuing changing environment of public sector organizations, (ii) generate 
contemporary empirical evidence that can provide a basis for designing management and leadership competency profiles/frameworks more relevant to the public sector; and (iii) conduct comparative analyses across societies with scholars banding together to develop country spanning studies. Our emic replication managerial behaviour study and cross-sector comparative analysis addresses in part Van Wart's calls, albeit within the SK national context. In so doing it attempts also to generate empirical evidence that will help advance current debate about the significance of the perceived 'difference' between public and private management. Specifically, our study has three aims: (i) to identify what behaviourally distinguishes effective managers from ineffective managers as perceived and judged by managers and non-managerial employees within a SK central government Ministry; (ii) to assess the extent to which these findings are similar or different to the findings of the aforementioned near equivalent SK private sectorrelated study; and (iii) where convergence occurs, to deduce (if possible) a set of discrete generic behavioral criteria and express them in the form of an emergent South Korean behavioural taxonomy of perceived managerial and leadership effectiveness.

\section{Literature Review}

Consistent with Hamlin et al. (2016) who followed Hamlin, Reidy and Stewart (1998), and Hamlin (2009) who had followed Yukl (1989), no rigid distinction is made in this study between the concepts of 'management' and 'leadership' even though many theorists argue there are distinct differences. The reason for this is because 'leading' is perceived by many scholars to be an integral aspect of the daily task of 'managing', and in many if not most organizations the two terms are blurred and used interchangeably (see Bolden, 2004; Frich, Brewster, Cherlin and Bradley, 2015; Mintzberg, 2004; Raelin, 2004, Yuk1, 2006). Hence, the term managerial behaviour embraces both managing-related and leading-related behaviours. The word 
'leadership' in the term perceived managerial and leadership effectiveness refers to the 'supervisory leadership' (House and Aditya, 1997) that every manager performs, and not to the type of 'strategic leadership' (House et al., 2004) that top managers and organizational leaders additionally perform. Furthermore, our use of this term embraces the processes of managing, leading, and guiding, which according to Van Wart (2013) constitute the administrative leadership performed by managers at all levels within public sector organizations.

\section{Indigenous management research in Asian countries}

According to Tsui (2007), indigenous research can be defined as any single country study that is context-specific as a result of either incorporating aspects of the national context in the theory and methods, or by taking the national context as granted which she states is the case for research conducted in the United States. From an Asia-Pacific perspective, Lyles (2009) and Li, Leung, Chen, and Luo (2012) argue that there are four types of indigenous research. We have generated a synthesis of their views (see Table 1) and discussed them elsewhere (see Hamlin, et al., 2016). INSERT Table 1 ABOUT HERE

We find that most management and leadership studies within Asian countries can be categorized as either Type 1 (emic-as-etic) indigenous research which applies extant Western theories in a naïve/uncritical way, or Type 2 (etic-to-emic) indigenous research which additionally involves a cross-context (cross-nation) comparative component aimed at modifying Western theories through identified constructs unique to the local phenomenon (if any). The primary aim of Type 3 (emic-as-emic) indigenous research is to build theories that can complement, supplement, supersede, or substitute Western theories. Other than our past SK private sector study and a recent equivalent private sector-related replication study carried out in India by Author 1 with a native Indian co-researcher (Hamlin et al., 2020), plus an exploration of managerial effectiveness 
within a state owned (profit-like) company in China by Wang (2011), we have found only two Type 3 manager/leader behavior-related studies in Asian countries, namely those of Cheng (1995), and Choi, Yoon and Jeung (2012). Type 4 (emic-and-etic) indigenous research involves the integration of the findings from Type 2 and Type 3 studies carried out in different local or global cultural contexts with the aim of building cross-cultural concepts, models, or theories. We know of no Type 4 managerial behavior research other than a study we conducted in parallel with our previously cited Type 3 SK private sector inquiry, the part results of which were compared against the findings of equivalent replication research in British private companies (Hamlin et al., 2016). Hence, little is known from indigenous management research in South Korea about people's perceptions and understanding of what behaviorally distinguishes effective managers from ineffective managers in public sector organizations, and whether these perceptions are similar or different to those of people within SK private companies. Our study attempts to address this gap in the public management/administration knowledge base.

\section{Difference between public versus private sector managerial competencies}

Various writers claim that the behavioural competence of managers is contingent upon the unpredictable and uncertain character of managerial work, and that behavioral competency frameworks cannot be transferred with equal success across organizations and organizational sectors (Argote and Fahrenkopf, 2016; Garavan and McGuire, 2001). Such claims lend support to those who argue that: (i) 'public sector', 'not-for-profit' and 'voluntary sector' organizations are inherently different from 'private (for-profit) sector' companies, that administrative leaders in the public sector behave differently from their counterparts in the business world, and that management theories do not apply equally across sectors (Andersen, 2010; Butler and Wilson, 1990; Orazi, Turrini and Valotti, 2013); and (ii) because of inherent sectoral differences in terms of culture, 
structure, values, and environment, public managers probably need to adopt different behaviours to those in private sector companies (see Chapman et al., 2016;_Ferguson, Ronayne, and Rybacki,.2014; Hansen and Villadsen, 2010; Van Der Wal, De Graaf and Lasthuizen, 2008). However, Hoojiberg and Choi (2001) point out that although "differences between public and private sector organizations have been studied in terms of job satisfaction and organizational commitment, motivation, and efficiency and effectiveness, few researchers have examined differences in leadership behaviour and effectiveness" (p. 404). Bourantis and Papalexandris (1993) found that public managers in Greece use less initiating structure in their leadership than private managers but the same amount of consideration; whereas in Sweden, Anderson (2010) found that task (initiating structure) styles of leadership are more often used in public sector organizations whilst relationship (consideration) styles are more often applied by private managers. In the UK, Dulewicz and Higgs (2005) found that the influence of managerial job contexts on a manager's leadership style appear to be the same in both organizational sectors. Thus, literature has been and continues to be inconclusive on the issue of managerial behaviour difference between sectors, which suggests more behavioural studies of managerial and leadership effectiveness are warranted.

\section{Theoretical context and research questions}

The theory that guides the empirical emic replication component of our study is the same as that which informed the previously cited SK private sector inquiry, namely: implicit leadership theory (ILT). Based on personally held ILT beliefs, convictions, and assumptions ('cognitive prototypes') about the attributes and behaviours associated with 'good (effective)' and 'bad' (ineffective) managers (Eden and Leviatan, 1975; Phillips and Lord, 1981), people use these to encode, process, and judge the actions and behaviours of managers with whom they interact (Cronshaw and Lord, 1987). The better the fit, the more likely it is that an observed manager 
will be perceived as being effective or, conversely, ineffective. The specific research questions we addressed were as follows:

RQ1. What is it that managers and non-managerial employees within a selected SK public sector organization perceive as effective and ineffective managerial behaviour?

RQ2. To what extent are the findings resulting from RQ1 similar or different to those that have resulted from equivalent SK private sector-related replication managerial behaviour research?

RQ3. Can the results of addressing RQ2 be expressed in the form of an emergent South

Korean generic behavioural taxonomy of perceived managerial and leadership effectiveness?

\section{Methods}

\section{Philosophical stance}

Most indigenous researchers and Western scholars who conduct management research in AsiaPacific countries: (i) adopt Western theoretical frameworks and constructs to inform research designs; (ii) apply and emphasize consistency with the dominant North American positivist research paradigm; (iii) underemphasize the need to develop theory that corresponds with and relies upon observations of the phenomena being studied; and (iv) address research problems derived from reviews of extant (mainly Western) literature research (see Leung, 2007; Leung and White, 2004; Li, 2012; Tsui, 2006; White, 2002). But as Tsui (2004; 2009) argues from a global management perspective, this 'normal science' approach risks discoveries being made that fall only within the field of inquiry that the Western theories and constructs privilege.

Consequently, in replicating what we did for our Type 3 (emic-as-emic) indigenous SK private sector inquiry (Chai et al. 2016), we adopted Tsui's (2007) 'definition' of indigenous 
research and assumed the same philosophical stance. This stance was based on: i) the pragmatic approach and notions of epistemological instrumentalism and abduction which allow researchers to assume a pluralist ontology and epistemology best suited to address the specified research questions, rather than being governed/privileged by the ontological-epistemological position of a particular research paradigm (Friedrichs and Kratochwil, 2009; Morgan, 2007; Saunders, Lewis and Thornhill, 2012); and ii) Eisenhardt and Graebner's (2007) method of theory building from multiple cases, and Mintzberg's (2017) understanding that theory development involves discovering patterns and recognizing similarities in things that might at first appear different. In addition, informed by Berry's (1989) derived etic approach to applied research, and Tsang and Kwan's (1999) notion of empirical generalization replication research, we adopted a post-positivist (empirical realist) ontology and a constructivist-interpretivist (transactional-subjectivist) epistemology (Bryman and Bell, 2003; Cunliffe, 2011; Hamlin, 2015). This philosophical approach is similar to qualitative positivism as discussed by Aguinis and Solarino (2019) in the field of strategic management research.

\section{Research design}

Our study is comprised of two component parts, as follows:

Component 1 (Addressing RQ 1)

Component 1 is a Type 3 indigenous managerial behaviour inquiry replicating not only the aforecited SK private sector study, but also equivalent public sector-related replication studies conducted in other non-Western nations including Egypt (Hamlin, Nassar, and Wahba, 2010) and Mexico (Hamlin, Ruiz, and Wang, 2011). As previously mentioned, the collaborating organization was a central government department (Ministry) in South Korea. Its senior officials 
(executives), middle officials (directors), and junior officials (deputy managers) were the subject focus of the inquiry which took place from January to October 2014.

\section{Sampling}

A purposive convenience sampling approach was used to secure a sample of research participants, the composition of which was informed by the multiple constituency (MC) model of organizational [and managerial] effectiveness as adopted by Tsui (1990), and by Author 1 for his previous managerial behaviour replication studies. According to Tsui (1990), "managers are perceived as operating within a social structure consisting of multiple constituencies or stakeholders (e.g. superiors, peers, subordinates, etc.), each of whom has his/her own expectations of and reactions to them" (see Hamlin, et al., 2016, p. 244). How their behaviour is perceived and judged by the respective constituencies determines their 'reputational effectiveness' (Tsui and Ashford, 1994), which in turn can lead to colleague managers either giving or withholding important information or co-operation, and their subordinates either following or ignoring their leadership. Thus, the sample was comprised of a near equal mix of managers $(n=24)$ and non-managerial employees $(n=21)$ who had volunteered to participate in the research; they were drawn from 11 of the 18 bureaus in the Ministry. This number of research informants $(\mathrm{n}=45)$ is consistent with Adler and Adler's (2012) recommended sample size of 12 to 60 participants for qualitative research with a mean of 30, and with Cresswell's (2013) advice to target 20 to 30 informants for grounded theory studies. Furthermore, experience from Author 1's previous equivalent replication managerial behaviour studies in public sector organizations within several other non-Anglo as well as in Anglo countries (see Hamlin, 2009), has shown that a point near to data saturation is typically reached with 40 to 50 informants. Of the 24 managers ( 8 directors and 16 deputy managers), 21 were male and 3 were female with ages ranging from 
the mid-30s to early-50s. Of the 21 non-managerial employees (office staff), 15 were males and 6 were females aged from the mid-20s to the late-30s. The sample did not (and could not) include any executive members (senior officials).

\section{Data collection}

Using Flanagan's (1954) critical incident technique (CIT), concrete examples (critical incidentsCIs) of effective and ineffective managerial behaviour were collected from the participants by Author 2 who is a bilingual South Korean living and working as an academic in the USA where she has been located and domiciled for over 11 years. Due to the distance and possible travel barriers plus cost implications, the data were collected through an e-mail interviewing process conducted in the Korean language. This involved using a CIT data collection sheet which had been translated into Korean by Author 2. In preparation, the participants were provided with definitions and explanations of the precise meaning of certain key terms-such as 'critical', 'incident' and 'critical incident'. The digital CIT interviewing involved the interviewees being asked to reflect on the past six to nine months, and recall up to a total of $10 \mathrm{CIs}$ of managerial behaviour which they had personally observed and, at the time, thought were examples of effective or ineffective managerial performance. The definitions and procedure for eliciting CIs from the research informants were as follows:

Effective managerial performance was defined as 'behaviour which you wish all managers would adopt if, and when faced with a similar circumstance.'

Ineffective managerial performance referred to 'behaviour which, if it occurred repeatedly or was seen once in certain circumstances, might cause you to begin to question or doubt the ability of that particular manager in that instance.' 
The CIs could include examples of behaviour exhibited by the interviewees' immediate managers, or by officials in positions higher up in the managerial hierarchy (superiors). If they held a managerial position, then additionally the CIs could include the behaviour exhibited by their colleague managers at the same level (peers), or officials who reported directly to them (subordinates). However, they were not allowed to describe CIs relating to their own managerial practice. Most offered 3 to 5 CIs of effective and of ineffective managerial behaviour which they recorded on the supplied CIT data collection sheets. In instances where a participant could have been more reflective in their answers, as would happen in a face to face CIT interview, or if participants had not fully answered the CIT questions, Author 2 posed follow-up or probing questions via email to elicit the causal link between the managerial behavior described and the respective recorded positive (effective) or negative (ineffective) outcomes/consequences. Alternatively, she contacted them by phone for additional information and explication.

The collected CIs were translated into English by Author 2, and independently by two bilingual South Korean students who were undertaking $\mathrm{PhD}$ programmes at the university in the USA where Author 2 is based. They then compared each of their respective translations to identify differences in their interpretations. Where discrepancies between the translations arose, these were resolved through a back-and-forth review process and discussion until a consensus was reached. The so translated CIs were then sent to Author 1 (a native mono-lingual Briton) for their meaning to be checked for clarity and specificity. Those CIs that appeared unclear or ambiguous were returned to Author 2 for further explication and follow up discussion. Any CIs still judged to be lacking in specificity or clarity of meaning were removed from further analysis.

\section{Data analysis}


Initially, Author 1 identified the unit of meaning (concept/code) of each translated CI by subjecting it to open coding at the semantic level of analysis (Flick, 2014). Those CIs with more than one identified unit of meaning were disentangled, and the resulting larger number of CIs were subsequently referred to as coded critical incidents (CCIs). The CCIs were subjected to inductive axial coding (Flick, 2014) to classify and group them into a maximum number of discrete behavioral categories. In accordance with the common CIT protocol used for the SK private sector study, each derived category was comprised of: (i) a minimum of 3 CCIs to minimize the likelihood of it reflecting the idiosyncratic behaviour of just one of the organization's managers, and (ii) a maximum of 12 CCIs to avoid a category being comprised of two or more discrete sub-categories. Each derived behavioural category was analyzed and interpreted to identify the meaning held in common with each of its constituent CCIs, and a behavioural statement (BS) then created to describe and label it.

\section{Component 2 (Addressing $R Q 2$ and $R Q 3$ )}

The Component 1 findings were compared against those resulting from the previously mentioned equivalent SK private sector-related study (see Hamlin, et al., 2016; Chai, et al., 2016). These private sector findings were comprised of 53 positive and 51 negative BSs derived from $571 \mathrm{CIs}$ collected from 45 research participants from over 20 of the largest companies in the Korea Fair Trade Commission's 2012 list of 100 best companies.

\section{Data analysis}

Initially, Author 1 compared the derived Component 1 SK public sector BSs against the obtained SK private sector BSs using 'realist qualitative analysis' (Madill, Jordon, and Shirley 2000). This involved open coding to identify the salient unit of meaning ( $1^{\text {st }}$-order concept) of each BS which was then subjected to axial coding to identify any sameness, or similarity, or just an element of congruence in meaning with at least one of the other BSs. Following Hamlin, et al. (2016) 
"Sameness was deemed to exist when the sentences or phrases used to describe two or more compared BSs were identical or near identical. Similarity was deemed to exist when the BS sentences and/or phrases were different, but the kind of meaning was the same. Congruence existed where there was an element of sameness or similarity in the meaning of certain phrases and/or key words" (p. 249). Where convergence was found the relevant BSs from the two SK studies were accordingly grouped and integrated into discrete behavioural categories comprised of public and private sector BSs. Each deduced category ( $2^{\text {nd }}$-order concept $)$ was interpreted for meaning and labelled accordingly with a short descriptive statement which we refer to as a 'generic behavioral indicator' (GBI).

The derived positive GBIs and negative GBIs were then subjected to selective coding to identify and elaborate a smaller number of 'core categories' around which they could respectively be clustered and thematically categorized (Flick, 2014). Where a negative GBI was 'near opposite' in meaning to one or more of the positive GBIs (i.e. it described an 'act of omission' and the absence of effective managerial behaviour), it was accordingly integrated into the behavioural content of the respective positive 'core category'. The clusters of negative GBIs that described 'acts of commission' were expressed as negative 'core categories'. Each deduced ‘core category' (i.e. $3^{\text {rd }}$-order aggregate dimension) was interpreted and given a label describing the overarching meaning of all its constituent GBIs. We refer to these dimensions as 'generic behavioral criteria' (GBCs).

The results of the analyses were first sent for independent code cross-checking (Gibbs, 2007) to Author 3 and Author 4 who, like Author 2, are native South Koreans working as university academics in the USA, and who are fluent in both languages. Where their interpretations and judgments in coding were found to diverge from those of Author 1, these 
were subjected to critical examination through a three-way discussion to reconcile differences. Once agreement was reached through several iterative digital exchanges, Author 1 sent the results to Author 2 for further code cross-checking. Where divergences arose, these were reconciled through discussion.

\section{Ensuring trustworthiness of the findings}

During the Component 1 CIT data collection phase, Author 2 engaged in member checking to ensure what had been recorded as a CI accurately reflected the meaning intended by the respective research participant. The internal validity (credibility) and reliability (dependability) of the Component 1 and Component 2 findings were ensured through a form of investigator triangulation (Easterby-Smith, Thorpe and Lowe, 1991) involving all four authors at various times acting as independent investigators. Author 1's coding, grouping, and integration of the Component 1 BSs and comparison against equivalent SK private sector BSs were independently and cumulatively code-cross checked by Author 3 and Author 4 (Madill et al., 2000). The plausibility (confirmability) and external validity (transferability) of the study findings were achieved: (i) through the mechanism of replication logic; and (ii) by conducting the cross-case comparative analysis to reach for generalizability using highly comparable empirical source data, albeit necessarily obtained from the equivalent SK private sector replication study due to the absence of a comparable SK public sector study.

\section{Results}

Component 1 research (Addressing RQ1)

A total of 355 CIs was collected from the 45 research participants of which 5 were discarded for reasons of ambiguity. The open coding of the remaining $350 \mathrm{CIs}$, of which several contained more than one unit of meaning (code/concept), resulted in a total of 188 effective CCIs and 189 
ineffective CCIs being identified. The axial coding of these CCIs yielded 66 discrete BSs of which 31 were indicative of positive (effective) and 35 of negative (ineffective) managerial behaviours, as shown in the left-hand column of Table 2 and listed in Table 3, respectively. INSERT Table 2 and Table 3 ABOUT HERE

As can be seen in the brackets at the end of each BS, the number of CCIs that underpin the positive BSs range from 3 to 11 (mean $n=6.16$ ), and those underpinning the negative BSs range from 3 to 8 (mean $n=5.43$ ). Overall, the derived set of 66 BSs provides an insightful and contextually relevant description of what behaviourally differentiates effective managers from ineffective managers within a SK central government department (Ministry).

Component 2 research (Addressing RQ2 \& RQ3)

Of the 31 positive SK public sector BSs, $93.55 \%(n=29)$ were found to be the same as, or similar to, or possess an element of congruence in meaning with $88.68 \%(n=47)$ of the positive SK private sector BSs, as can be seen in Table 2 where the two sets of convergent BSs have accordingly been juxtaposed against each other. Due to anticipated word count restrictions we have not presented the results of comparing the negative SK public sector BSs against the equivalent negative SK private sector BSs, but they are obtainable from the corresponding author. Of the 35 negative SK public sector BSs, $100.00 \%(n=35)$ are the same as, or similar to, or contain an element of congruence in meaning with $94.12 \%(n=48)$ of the negative SK private sector BSs.

Interpretation of the overarching meaning of the derived categories of juxtaposed SK public and SK private sector BSs led to the identification of: i) 20 deduced positive GBIs of perceived managerial and leadership effectiveness ( $\mathrm{P} 1$ to $\mathrm{P} 20$ ) as listed in the right-hand column of Table 2; and ii) 25 negative GBIs (N1 to N25). Details of how the derived negative GBIs 
were deduced from the cross-case comparative analysis of negative SK public and private sectors BSs are not presented in this paper, but their descriptive labels can be seen in the right-hand column of Table 4. The selective coding of the sets of derived positive and negative GBIs led to the identification of 11 positive (effective) generic behavioural criteria (GBCs) and 4 negative (ineffective) GBCs (see Table 4 typed in bold). These constitute what we suggest is as an emergent South Korean behavioural taxonomy of perceived managerial and leadership effectiveness (see Table 5). To provide transparency of our cross-case/cross-sector comparative INSERT Table 4 and Table 5 NEAR HERE analysis process, and how we progressed from 'raw' empirical data (BSs) to aggregate dimensions (GBCs), we have constructed a graphical representation in the form of a data structure in accordance with the 'Gioia, methodology for building rigour into inductive qualitative research' (Gioia, Corley and Hamilton, 2012) (see Figure 1)

\section{INSERT Figure 1 ABOUT HERE}

\section{Discussion}

This paper began with a discussion of the dearth of Type 3 (emic-as-emic) indigenous management research in Asian countries, including South Korea, and the paucity of contemporary managerial behaviour research in public sector organizations, not only in South Korea but also worldwide. Our study has addressed these gaps by identifying 66 behavioural categories (BSs) of effective and ineffective managerial behaviour deduced from perceptions and descriptions of the lived experiences of managers and non-managerial employees within a SK central government department (Ministry). We know of no other indigenous emic qualitative study of the behavioural effectiveness of public managers that has been carried out in South Korea. Our study has also addressed in a tentative way the dearth of indigenous Eastern 
management-related theory by identifying an emergent SK behavioural taxonomy through 'replication logic' and Type 4 (emic-and-etic) indigenous cross-case/cross-sector comparative analysis.

\section{Theoretical contribution}

Interestingly, $96.97 \%(\mathrm{n}=66)$ of the derived SK public sector BSs are convergent in meaning with $91.35 \%(\mathrm{n}=95)$ of the compared SK private sector BSs; this is higher than expected bearing in mind the amount of recent literature claiming divergence (difference). Furthermore, the two derived SK public sector BSs that do not converge in meaning with any SK private sector BS show no evidence of being sector-specific (see Table 2); nor do any of the six non-convergent SK private sector BSs. The identified high degrees of convergence between people's perceptions of the behavioural effectiveness of managers within public and private sector organizations, and the apparent lack of detectable sector-specific managerial behaviors albeit within the South Korean national context, lend no empirical support to : i) those who theorize that the behavioural competence of managers is contingent upon the sectoral context; and ii) those who argue that to be effective public managers need to adopt different managerial and leadership behaviours and styles to those of private managers because of inherent sectoral differences such as culture, structure, values, and environment (Anderson, 2010; Hansen and Villadsen, 2010; Van Der Wal et al., 2008). On the contrary, our findings support Rainey and Chun (2007) who claim that whatever difference or distinction may exist, it is not worth much. Instead, the results of our research_suggest that to be perceived effective, managers in both SK public and private sector organizations need to: Exhibit good judgement and make well-informed decisions based on evidence and a clear understanding of issues; Be good at organising and directing including the fair allocation of roles, tasks and workloads and giving clear instructions; Be proactive in 
developing and utilizing improved work methods; Proactively monitor and control staff performance and resolve problems; Exhibit active supportive management/leadership behaviour; Delegate effectively and empower staff; Take an interest in staff and show care and concern for their well-being; Develop an open and trusting relationship with staff; Actively provide guidance and training, and support their personal self-development; Be open to ideas and the thinking of others, and involve staff; and communicate well with staff and also keep them informed on key issues. Furthermore, they need to avoid exhibiting inappropriate autocratic behaviour; selfish and self-serving behaviour; undermining behaviour; and avoidance behaviour.

We suggest the 11 positive and 4 negative GBCs and their respective underpinning GBIs constituting the behavioural dimensions of our emergent SK behavioural taxonomy of perceived managerial and leadership effectiveness, provide a distinctive indigenous understanding of what behaviourally differentiates effective SK managers from ineffective SK managers. Furthermore, the range of positive and negative BSs resulting from our present SK public sector study, as well as those that had resulted from our previous SK private sector study, are also distinctive in terms of being the product of Type 3 (emic-as-emic) indigenous research carried out within an AsiaPacific country. A further distinction of both replication studies is the near equal emphasis given to exploring ineffective as well as effective managerial behaviour. This holistic balance of focusing on the two sides of managerial behavioural effectiveness is in sharp contrast to most past Western managerial and leadership effectiveness-related studies which have focused mainly on effective behaviour. Other than a few studies of toxic management/leadership exhibited by top managers (see for example Padilla, Hogan, and Kaiser, 2007), little attention has been given to the everyday least effective/mundane ineffective behaviours of managers at other levels of management. Yet a two-sided approach is considered important because according to Amabile 
et al. (2004), ineffective behaviour can be more significant than effective behaviour in influencing subordinate performance. Additionally, the affective reactions of subordinates to mundane ineffective managerial behaviours, or even to just a single toxic managerial behaviour, can have a much stronger impact than numerous positive managerial behaviours.

Our emergent two-sided SK behavioural taxonomy of perceived managerial and leadership effectiveness has been deduced wholly from empirical data generated within a single country context. Hence, in accordance with Tsui's (2007) definition of indigenous research, and following Cammock, Nilakant and Dakin (1995), it could be described as an indigenous theoretical 'two-factor' (taxonomic) model. This, we believe, is a rare form of Eastern mid-range theory development through a process of Type 3 indigenous empirical generalization replication research (Tsang and Kwan, 1999) and Type 4 indigenous cross-case comparative analysis (Eisenhardt, 1989; Eisenhardt and Graebner, 2007).

\section{Implications for practice}

Much formal management and leadership development (MLD) in Asian countries has relied historically on Western theories, models, and concepts derived from empirical research conducted mostly within the USA. Furthermore, such MLD programmes have been delivered mostly in accordance with traditional Western philosophies of education. However, Johansen and McLean (2006) claim that such approaches to global talent management may not be wholly appropriate for training and promoting indigenous managers who may culturally have different perspectives on effective and ineffective management/leadership. We suggest MLD programmes based on our emergent Eastern derived SK behavioural taxonomy are likely to strike a much stronger chord with SK managers than MLD programmes based on Western derived theories, models, and taxonomies. This is because any conscious or unconscious prejudice that 
SK managers may have against Western know-how could not come into play. Hence, our emergent SK behavioural taxonomy could be particularly useful to human resource development (HRD) practitioners seeking to develop more effective organizational plans for the training and development of SK managers, and/or for preparing expatriate managers from other countries to manage and lead South Korean employees. Specifically, the identified SK generic behavioural criteria (GBCs) could be used to critically evaluate the efficacy of any extant MLD programme, or to inform/shape the creation of a new MLD programme. Additionally, they could be used by other HR professionals within organizations to evaluate extant or to inform the creation of new assessment criteria for management selection and/or performance appraisal systems. Furthermore, the constituent GBCs of our emergent SK behavioural taxonomy could be used for the same purposes in other SK public sector organizations and SK private companies, though with some caution until it has been empirically demonstrated as being generalized to more public and private sector organizations within South Korea.

Interestingly, a quick comparison of our 15 deduced positive (effective) and negative (ineffective) SK GBCs against 14 GBCs constituting a 'British (behavioral) taxonomy of perceived managerial and leadership effectiveness' offered by Hamlin and Hatton (2013), reveals a high degree of sameness and similarity. We find $86.67 \%(n=13)$ of the South Korean derived GBCs convergent in meaning with all or part of $85.71 \%(n=12)$ of the British derived GBCs. Hence, a high proportion of both these nation-specific derived behavioural taxonomies are held in common. This means most parts of the British taxonomy are relevant and potentially transferable to the SK context, and most parts of our South Korean deduced taxonomy are relevant and transferable to the UK context. However, despite this high level of convergence, we suggest managers and employees as well as MLD/HRD practitioners in South Korea would likely take 
more cognizance of our emergent SK taxonomy than of the British taxonomy. This is because: i) it has been_derived wholly from empirical evidence generated by inductive local (nation-specific) indigenous research; and ii) disillusionment with Western theories as reported by Lyles (2009) which, we suggest, is likely still to persist in Asia-Pacific countries.

\section{Limitations of the study and directions for future research}

Our study has three limitations as follows: First, time constraints during the Component 1 stage prevented CIT data being obtained from more than 45 research participants. This may have precluded the point of 'data saturation' having been reached. Hence, it is possible that there are other discrete categories of effective and ineffective managerial behaviour that might emerge from future research within the specific context of our collaborating public-sector organization. Second, although these single organization SK public sector (central government) findings have been externally validated by comparing them against those resulting from our prior SK private sector study, their generalizability to other specific central government departments or other types of public sector organization in South Korea has yet to be demonstrated empirically. Hence, more Type 3 (emic-asemic) indigenous replication managerial behaviour studies should be carried out in various sub-areas of the SK public sector, with the aim of identifying (if possible) the existence of GBIs of perceived managerial and leadership effectiveness that are relevant and transferable across the whole sector. Third, the subject focus of the current study was on senior, middle, and first line managers and supervisors. Hence, it would be meaningful to include top managers and executive leaders in the subject focus of future studies, or alternatively to conduct follow up inquiries focused solely on the managerial behaviours manifested by members of top management teams. Another direction for future research would be for multiple Type 3 indigenous replication managerial behaviour studies also to be carried out in the SK private sector, and together with the additional SK public sector 
studies, for the results of these to be used to 'test' and refine our emergent South Korean behavioural taxonomy.

\section{Conclusion}

We believe our Component 1 research is the first Type 3 (emic-as-emic) indigenous qualitative study of effective and ineffective managerial behaviour within the SK public sector; and our Component 2 research is the first Type 4 (emic-and-etic) indigenous cross-sector comparison of findings against equivalent findings from the SK private sector. It is our hope that the inquiry will: (i) act as a catalyst for more dialogue regarding indigenous research, not only within the SK context but also in other national contexts in the Asia-Pacific Region; and (ii) encourage future researchers to engage in these more advanced types of indigenous managerial behaviour studies that can lead to Eastern mid-range theory development through replication research.

\section{References}

Adler, P. A. and Adler, P. (2012), "How many qualitative interviews is enough?" in Baker, S. E. and Edwards, R. (Eds), How Many Qualitative Interviews Is Enough? Expert Voices and Early Career Reflections on Sampling and Cases in Qualitative Research (pp.8-11), ESRC National Centre for Research Methods, University of Southampton, Southampton, UK. Aguinis, H., and Solarino, A. M. (2019), “Transparency and replicability in qualitative research: The case of interviews with elite informants", Strategic Management Journal, Vol. 40 No.8, pp. 1291-1315.

Argote, L., and Fahrenkopf, E. (2016), "Knowledge transfer in organizations: The roles of members, tasks, tools, and networks", Organizational Behavior and Human Decision Processes, Vol. 136, pp. 146-159. 
Amabile, T. M., Schatzel, E. A., Moneta, B. and Kramer, S. J. (2004), "Leader behaviors and work environment for creativity: Perceived leader support”, The Leadership Quarterly, Vol. 15, pp. 5-32.

Anderson, J. A. (2010), "Public versus private managers: How public and private managers differ in leadership behavior", Public Administration Review, Vol. 70 No. 1, pp. 131-141.

Berry, J. W. (1989), "Imposed etics-emics-derived etics: The operationalization of a compelling idea”, International Journal of Psychology, Vol. 24, pp. 721-735.

Bolden, R. (2004), What is Leadership? Leadership South West Research Report, South West of England Regional Development Agency, Exeter, UK:

Bourantas, D., and Papalexandras, N. (1993), "Differences in leadership behaviour and influence between public and private organizations in Greece", International Journal of Human Resource Management, Vol. 4 No. 4, pp. 859-871.

Bryman, A. and Bell, E. (2015), Business Research Methods, Oxford University Press, Oxford, UK.

Butler R. J. and Wilson, D. (1990), Managing Voluntary and Non-profit Organizations: Strategy and Structure, Routledge, London, UK.

Cammock, P., Nilakant, V. and Dakin, S. (1995), "Developing a lay model of managerial Effectiveness", Journal of Management Studies, Vol. 32 No. 4, pp. 443-447.

Chai,D-S., Jeong, S., Kim, J., Kim, S., and Hamlin, R. G. (2016), "Perceived managerial and leadership effectiveness in a Korean context: An indigenous qualitative study”, Asia Pacific Journal of Management, Volume 33 No. 3, pp. 789-821.

Chapman, C., Getha-Taylor, H., Holmes, M. H., Jacobson, W. S., Morse, R. S. and Sowa, 
J. E. (2016), "How public service leadership is studied: An examination of a quarter century of scholarship", Public Administration, Vol. 94 No. 1, pp. 111-128.

Cheng, B. S. (1995), "Paternalistic authority and leadership: A case of a Taiwanese CEO", Bulletin of the Institute of Ethnology Academic Sinica, Vol 79, pp.171 (in Chinese).

Choi, M., Yoon, H.J. and Jeung, C. (2012), "Leadership development in Korea: A Delphi study", Asia Pacific Journal of Human Resources, Vol. 50, pp. 23-42.

Cresswell, J. W. (2013), Qualitative Inquiry \& Research Design: Choosing Among Five Approaches ( ${ }^{\text {rd }}$ ed), Sage, Thousand Oaks, CA.

Cronshaw, S. E. and Lord, R. G. (1987), "Effect of categorization, attribution, and encoding processes on leadership perceptions", Journal of Applied Psychology, Vol. 72, pp. 97-106.

Cunliffe, A. L. (2011), “Crafting qualitative research: Morgan and Smircich 30 years on”, Organizational Research Methods, Vol. 14 No. 4, pp. 647-673.

Dulewicz, V. and Higgs, M. (2005), “Assessing leadership styles and organizational context”, Journal of Managerial Psychology, Vol. 20 No. 2, pp. -123.

Easterby-Smith, M., Thorpe, R. and Lowe, A. (1991), Management Research: An Introduction, Sage, London, UK.

Eden, D. and Leviatan, U. (1975), "Implicit leadership theory as a determinant of the factor structure underlying supervisory behavior scales", Journal of Applied Psychology, Vol. 72, pp.97-106.

Eisenhardt, K. M. (1989), "Building theories from case study research”, Academy of Management Review, Vol. 14, pp. 532-550.

Eisenhardt, K. M., and Graebner, M. E. (2007), “Theory building from cases: Opportunities and 
challenges", Academy of Management Journal, Volume 50 No. 1, pp. 25-32.

Ferguson, J., Ronayne, P. and Rybacki, M. (2014), Public Sector Leadership Challenges: Are They Different and Does It Matter?, Center for Creative Leadership, Greensboro, NC.

Flanagan, J. C. (1954), “The critical incident technique”, Psychological Bulletin, Vol. 51, pp. 327-358.

Flick, U. (2014), An Introduction to Qualitative Research (5 $\left.{ }^{\text {th }} \mathrm{ed}\right)$, Sage, London, UK.

Frich, J. C., Brewster, A. L., Cherlin, E. J. and Bradley, E. H. (2014), “Leadership development programs for physicians: A systematic review", Journal of General Internal Medicine, Vol. 30 No. 5, pp. 656-674.

Friedrichs, J. and Kratochwil, F. (2009), “On acting and knowing: How pragmatism can advance international relations research and methodology", International Organization, Volume 63 No. 4, pp. 701-731.

Garavan, T. and McGuire, D. (2001), "Competencies and workplace learning: Some reflections on the rhetoric and the reality", Journal of Workplace Learning, Vol.13 No. 4, pp. 144163.

Getha-Taylor, H., Holmes, M.H., Jacobson, W.S., Morse, R. S., and Sowa, J.E. (2011) "Focusing the public leadership lens: Research propositions and questions in the Minnowbrook tradition"; Journal of Public Administration Research and Theory, Volume 21 No.1, pp. 83-97.

Gibbs, G. R. (2007), Analyzing Qualitative Data, Sage, London, UK.

Gioia, D. A., Corley, K. G., and Hamilton, A. L. (2012), "Seeking qualitative rigor in inductive research: Notes on the Gioia methodology", Organizational Research Methods, Vol.16 No.1, pp.15-31 
Hamlin, R. (Bob) G. (2015), "Paradigms, philosophical prisms and pragmatism in HRD research", in Saunders, M. N. K. and Tosey, P. (Eds), Handbook of Research Methods on Human Resource Development (pp. 13-31), Edward Elgar Publishing. Cheltenham, UK.

Hamlin, R. (Bob) G. (2009), Universalistic Models of Managerial and Leadership Effectiveness: A Cumulative and Multiple Cross-Case Empirical Study of Effective and Ineffective Managerial Behaviour, VDM Verlag Publishing, Saarbrucken, Germany.

Hamlin, R. G. and Hatton, A. (2013), “Toward a British taxonomy of perceived managerial and leadership effectiveness", Human Resource Development Quarterly, Vol. 24 No. 3, pp. $365-406$

Hamlin, R. G., Kim,S., Chai,D-S., Kim, J., and Jeong, S. (2016), "Perceived managerial and leadership effectiveness with South Korean and British private companies: A derived etic comparative study", Human Resource Development Quarterly, Vol. 27 No. 2, pp. 237269.

Hamlin,R .G., Nassar, M., and Wahba, K., (2010), "Behavioural criteria of managerial and leadership effectiveness within Egyptian and British public sector hospitals: An empirical study and multiple-case/cross-nation comparative analysis", Human Resource Development International, Vol. 13 No. 1, pp. 45-64.

Hamlin, R. G., and Patel, T. 2020), “Toward an emergent Asian behavioural model of perceived managerial and leadership effectiveness: A cross-nation comparative analysis of effective and ineffective managerial behavior of private sector managers in India and South Korea”, Human Resource Development International, Vol. 23 No.3, pp. 259-282. 
Hamlin, R. (Bob) G., Reidy, M., and Stewart, J. D. (1998), "Bridging the HRD research-practice gap through professional partnerships: A case study", Human Resource Development International, Vol. 1 No. 3, pp. 273-290.

Hamlin, R. G., Ruiz,C. E., and Wang, J. (2011), "Perceived managerial and leadership effectiveness within Mexican and British public sector hospitals: An empirical study and cross-nation comparative analysis”, Human Resource Development Quarterly, Vol. 22 No.4, pp. 491-518.

Hansen, J. R. and Villadsen, A. R. (2010), “Comparing public and private managers' leadership styles: Understanding the role of job context”, International Public Management Journal, Vol. 1 No. 3, pp.247-274.

Head, B. W. (2010), "Public management research: Towards relevance", Public Management Review, Vol. 12 No. 5, pp. 571-585.

Hooijberg, R. and Choi, J. (2001), “The impact of organizational characteristics on leadership effectiveness models: An examination of leadership in a private and a public sector organization", Administration \& Society, Vol. 33 No. 4, pp. 403-431.

House, R. and Aditya, R. (1997), “The social scientific study of leadership: Quo vadis?”, Journal of Management, Vol. 23, pp. 409-465.

House, R. J., Hanges, P. J., Javidan, M., Dorfman, P. W. and Gupta, V. (2004), Culture, Leadership, and Organizations: The GLOBE Study of 62 Societies, Sage, London, UK.

Johansen, B-C. P. and McLean, G. N. (2006), "Worldviews of adult learning in the workplace: A core concept in human resource development", Advances in Developing Human Resources, Vol. 8 No. 3, pp. 321-328. 
Leslie, K., and Canwell, A. (2010), "Leadership at all levels: Leading public sector organizations in an age of austerity", European Management Journal, Vol. 28, pp. 297-305.

Leung, K. (2007), "The glory and tyranny of citation impact: As East Asian perspective", Academy of Management Journal, Vol. 50, pp. 510-513.

Leung, K. and White, S. (2004), Handbook of Asian Management, Kluwer Academic, Boston, MA.

Li, P. P. (2012), "Toward an integrative framework of indigenous research: The geocentric implications of Yin-Yang Balance", Asia Pacific Journal of Management, Vol. 29, pp. 849-872.

Li. P. P., Leung, K., Chen, C. C. and Luo, J-D. (2012), “Indigenous research on Chinese management: What and how", Management and Organization Review, Vol. 8, pp, 7-24.

Li, P. P., Zhou, K. and Sekiguchi, T. (2014), “Call for papers: Special issue on indigenous management research in Asia”, Asia Pacific Journal of Management. Retrieved from http://www.iacmr.org/v2en/Detail.asp?id=413

Lyles, M. (2009), "Call for proposal submission for dissertation grant and workshop", International Association for Chinese Management Research. Retrieved from http://www.iacmr.org/Publications/MOR/IndigenousResearch/Definition\%20of\%20Indig enous\%20Research\%20MOR.pdf

Madill, A., Jordon, A. and Shirley, C. (2000), "Objectivity and reliability in qualitative analysis: Realist, contextualist and radical constructionist epistemologies", British Journal of Psychology, Vol. 91, pp. 1-20. 
Morgan, B. L. (2007), "Paradigms lost and pragmatism regained: Methodological implications of combining qualitative and quantitative methods", Journal of Mixed Methods Research, Vol. 1, pp. 48-76.

Mintzberg, H. (2004), Managers Not MBAs: A Hard Look at the Soft Practice of Managing and Management Development, Berrett-Koehler, San Francisco, CA.

Mintzberg, H. (2017), "Developing theory about the development of theory" in Floyd, S. W. and Wooldridge, B. (Eds), Handbook of Middle Management Strategic Process Research (pp. 177-196), Edward Elgar Publishing. Cheltenham, UK.

Orazi, D. C., Turrini, A. and Valotti, G. (2013), "Public sector leadership: new perspectives for research and practice", International Review of Administrative Sciences, Vol. 79 No. 3, pp. 486-504

O’Toole, L. J., Meier, K. J. and Nicholson-Crotty, S. (2005), "Managing upward, downward and outward”, Public Management Review, Vol. 7 No. 1, pp. 45-68.

Padilla, A., Hogan, R. and Kaiser, R. B. (2007), “The toxic triangle: Destructive leaders, susceptible followers, and conducive environments", The Leadership Quarterly, Vol. 18, pp. 176-194.

Phillips, J. S. and Lord, R. G. (1981), "Causal attributions and perceptions of leadership", Organizational Behavior and Human Performance, Vol. 28, pp. 58-83.

Raelin, J. (2004). "Don't bother putting leadership into people", Academy of Management Executive, Vol. 18 No. 3, pp. 340-355.

Rainey, H. G. and Chun, Y. H. (2007), "Public and private management compared" in Ferlie, E., Lynn Jr., L. E., and Pollitt, C. (Eds), The Oxford Handbook of Public Management (pp. 72-102), Oxford, UK., 
Saunders, M., Lewis, P. and Thornhill, A. (2012), Research Methods for Business Studie,. Pearson Education, Harlow, UK.

Tsang, E. W. K. and Kwan, K-M. (1999), "Replication and theory development in organizational science: A critical realist perspective”, Academy of Management Review, Vol. 24, pp. 759-780.

Tsui, A. S. (1990), “A multiple-constituency model of effectiveness: An empirical examination at the human resource subunit level", Administrative Science Quarterly, Vol. 35, pp. 58-483.

Tsui, A. S. (2004), “Contributing to global management knowledge: A case for high quality indigenous research”, Asia Pacific Journal of Management, Vol. 21 No. 4, pp. 491-513.

Tsui, A. S. (2006), “Contextualization in Chinese management research”, Management and Organization Review, Vol. 2, pp. 1-13.

Tsui, A. S. (2007), "From homogenization to pluralism: International management research in the Academy and beyond", Academy of Management Journal, Vol. 50, pp. 353-1364.

Tsui, A. S. (2009), “Editor's Introduction-autonomy of inquiry: Shaping the future of emerging scientific communities", Management and Organization Review, Vol. 5, pp. 1-14.

Tsui, A. S. and Ashford, S. J. (1994), “Adaptive self-regulation: A process view of managerial effectiveness", Journal of Management, Vol. 20, pp. 90-121.

Van Der Wal, Z., De Graaf, G. and Lasthuizen, K. (2008), "What's valued most? Similarities and differences between the organizational values of the public and private sector", Public Administration, Vol. 86 No. 2, pp. 465-482.

Van Wart, M. (2003), "Public-sector leadership theory: An assessment”, Public Administration Review, Vol. 63 No. 2. pp.214-228. 
Van Wart, M. (2013), “Administrative leadership theory: A reassessment after 10 years”, Public Administration, Vol. 91 No. 3, pp. 521-543.

Vogel, R. and Masal, D. (2015), "Public leadership: A review of the literature and framework for future research", Public Management Review, Vol. 17 No. 8, pp. 1165-1189.

Wallis, J. and McLoughlin, L. (2007), "A diagnosis of leadership effectiveness in the Irish public sector", Public Management Review, Volume 9 No. 3, pp. 327-351.

Wang, J. (2011), "Understanding managerial effectiveness: A Chinese perspective”, Journal of European Industrial Training, Vol. 35, pp. 6-23.

White, S. (2002), "Rigor and relevance in Asian management research: Where are we and where can we go?", Asia Pacific Journal of Management, Vol. 19, pp. 287-352.

Yukl. G. (1989), "Managerial leadership: A review of theory and research”, Journal of Management, Vol. No. 2, pp. 254-289.

Yuk1, G. (2006), Leadership in Organizations. (6 ${ }^{\text {th }}$ Ed.), Pearson, Upper Saddle River, NJ. 


\section{Table 1 Four types of indigenous research}

Type 1 (Emic-as-etic [or imposed etic] with mostly Western content).

Involves a naïve/uncritical application of existing Western theories in Eastern contexts with the aim of applying, verifying, or confirming them. The research may qualify as indigenous if it draws attention to certain local uniqueness or perspectives

Type 2 (Etic-to-emic with imbalanced Western-Eastern content).

A more advanced approach with the primary aim of modifying and revising Western theories though cross-context comparative analysis

Type 3 (Emic-as-emic with mostly Eastern content).

An innovative approach with the primary aim of building Eastern theories that can complement, supplement, supersede, or substitute Western theories by identifying and/or developing novel local constructs to explain local phenomena.

Type 4 (Emic-and-etic [derived etic] integration with well-balanced local-global or Eastern-Western content).

The most advanced approach aimed at building cross-cultural constructs/theories and developing geocentric (emicand-etic) knowledge through the integration of emic theories resulting from Type 2 and Type 3 studies carried out in different local/cultural contexts.

Note: The term geocentric "refers to a mosaic-style integration of an etic theme (the global core) with all the diverse emic versions (the unique local details) of the etic theme, thus becoming culture-integrative" (Lyles, 2009, p. 1).

Source: Hamlin et al. (2016) 
Table 2 SK public sector derived positive BSs compared against equivalent SK private sector BSs plus the derived emergent positive SK generic behavioural indicators

\begin{tabular}{|c|c|c|}
\hline $\begin{array}{l}\text { SK Public Sector Study } \\
\text { Positive BSs }(\mathrm{n}=31)\end{array}$ & $\begin{array}{l}\text { SK Private Sector Study } \\
\text { Positive BSs }(n=53)\end{array}$ & $\begin{array}{l}\text { Derived SK Generic } \\
\text { Behavioural Indicators } \\
\text { Positive GBIs }(n=20)\end{array}$ \\
\hline $\begin{array}{l}\text { (1) Manager obtains/uses best data } \\
\text { and/or expertise of others for } \\
\text { developing policies and plans } \\
\text { ( } 3 \text { CCIs) }\end{array}$ & $\begin{array}{l}\text { (1) A manager formulates/implements } \\
\text { his/her strategies/plans [(i.e., goals or } \\
\text { plans)] and gives team members } \\
\text { directions/guidelines based on a clear } \\
\text { understanding of his/her own superior's } \\
\text { intentions, opinions and overarching } \\
\text { direction [(i.e., higher management } \\
\text { goals)] with nun-chi } \\
\text { (6) Based on an analysis and } \\
\text { understanding of the business } \\
\text { environment and trends, a manager } \\
\text { develops long term plans (i.e., visions } \\
\text { or goals) and shares these with his/her } \\
\text { subordinates/team }\end{array}$ & $\begin{array}{l}\text { P1) Develops plans and } \\
\text { policies based on best } \\
\text { evidence derived from } \\
\text { analysis and/or expertise } \\
\text { of others, plus a clear } \\
\text { understanding of the } \\
\text { strategic direction of } \\
\text { higher management }\end{array}$ \\
\hline $\begin{array}{l}\text { (2) Manager finds best methods to } \\
\text { achieve maximum } \\
\text { efficiency/productivity/waste } \\
\text { minimization ( } 7 \text { CCIs) }\end{array}$ & $\begin{array}{l}\text { (2) A manager } \\
\text { systematizes/standardizes task/work } \\
\text { routines/processes and/or creates work } \\
\text { manuals with his/her expertise } \\
\text { (3) A manager simplifies work } \\
\text { processes by eliminating unnecessary } \\
\text { tasks and formality, based on his/her } \\
\text { experience, and/or encourages his/her } \\
\text { subordinates to do the same } \\
\text { (4) A manager effectively plans and } \\
\text { prioritizes work, tasks } \\
\text { and assignments to achieve efficient } \\
\text { use of time and resources based on } \\
\text { his/her expertise }\end{array}$ & $\begin{array}{l}\text { P2) Takes action to } \\
\text { improve working } \\
\text { methods, processes, and } \\
\text { productivity }\end{array}$ \\
\hline $\begin{array}{l}\text { (3) When required the manager } \\
\text { takes immediate or timely action to } \\
\text { get speedy decisions and develop } \\
\text { action plans ( } 10 \text { CCIs) }\end{array}$ & $\begin{array}{l}\text { (7) A manager makes quick and timely } \\
\text { decisions in ambiguous and } \\
\text { unambiguous situations based on an } \\
\text { understanding of a context (nun-chi) } \\
\text { (8) A manager takes the initiative and } \\
\text { acts as a role model in adapting to and } \\
\text { implementing desired organizational } \\
\text { changes }\end{array}$ & $\begin{array}{l}\text { P3) Takes the initiative } \\
\text { and makes timely } \\
\text { decisions in executing } \\
\text { plans }\end{array}$ \\
\hline $\begin{array}{l}\text { (4) Manager anticipates/identifies } \\
\text { [through monitoring] potential } \\
\text { [performance] problems and } \\
\text { proactively takes the initiative to } \\
\text { act [e.g. providing feedback] ( } 9 \\
\text { CCIs) }\end{array}$ & $\begin{array}{l}\text { (11) A manager evaluates/appraises } \\
\text { his/her subordinates' performance and } \\
\text { provides feedback based on objective } \\
\text { facts and not subjective emotion or } \\
\text { personal feelings ( } k i \text {-bun) } \\
\text { (12) A manager provides specific } \\
\text { and/or systematic feedback on a } \\
\text { subordinate's role behaviour, } \\
\text { performance and/or mistakes }\end{array}$ & $\begin{array}{l}\text { P4) Proactively monitors } \\
\text { staff performance and/or } \\
\text { progress and provides } \\
\text { constructive feedback }\end{array}$ \\
\hline
\end{tabular}


(35) A manager continuously shows an interest in and checks/monitors an employee's progress throughout the performance of their tasks, and provides them with constructive comments

(36) A manager provides at the right time, helpful feedback to his/her subordinates on and/or throughout the duration of their work processes

(37) A manager frequently or constantly checks up on the task progress of his/her subordinates and provides useful feedback in the form of comments, guidance, solutions, or directions to help or to praise their performance

(5) When a member of staff, or the team, or another department is under excessive pressure or in some difficulty, the manager personally jumps in to lend practical support and/or willingly provides help (9 CCIs)
(13) When a problem arises, a manager focuses on solving it rather than finding fault in the employees and blaming them

(15) A manager helps and supports employees engaged in crossdepartmental projects who face difficulties or cannot solve problems caused by their lower rank or lack of experience/expertise

(6) Manager compliments staff and give them credit for their effort and contribution (3 CCIs)

(21) A manager acknowledges and gives recognition and praise to his/her subordinates for their good performance and successes

(22) A manager rewards his/her subordinates when they achieve their goals and/or when they work overtime in their personal/family time (e.g., on a night or at weekends) and/or pays them a visit to provide encouragement

(7) Manager supports internal and/or external staff and/or networks with advice and guidance as and when needed (10 CCIs)

(16) A manager strives to support his/her subordinates (i.e., feedback, help comments, or action) when they ask for

(34) A manager suggests helpful tips after noting a deficiency in his/her subordinate's work instead of criticizing

(8) Manager shields/protects staff from direct top down directions, orders or proposals from higher management that could create difficulties for or be unfair to their staff (5 CCIs)

(9) Manager steps in and resolves problems originating within the
(17) When empowering employees to make decisions on tasks delegated to them or when overriding a team member who objects to a team decision, the manager takes full responsibility for any adverse consequences

(18) A manager will disagree with and find alternative solutions to
P5) Provides practical help and support to staff/team and/or colleagues when faced with problems or in difficult situations

\section{P6) Gives recognition, praise, credit, and/or reward to staff for their good performance}

P7) Provides advice and guidance to staff as and when needed 


department or resulting from other
departments which create
difficulties for his/her own staff
(6 CCIs)

(10) Manager protects staff from outside criticism and/or takes action to protect the image of the department (8 CCIs)

(11) Manager delegates effectively and empowers staff to take on key tasks and to use their own initiative in their work (6 CCIs) decisions/orders from higher management that he considers not right for the smooth running of his department

(19) When his/her team as a whole makes a mistake, or has a problem with other teams, he/she protects team members and takes responsibility for it

(27) A manager actively delegates authority and responsibility to his/her subordinates, and trusts their capabilities to be in charge of work and to deliver the required results

(28) A manager empowers his/her subordinates to take the initiative, selfdirect and/or report their own work to senior management

(12) When a member of staff is experiencing a personal, domestic, or health problem/issue affecting their ability to perform to standard, the manager offers some flexibility in his/her expectations (3 CCIs)
(30) A manager understands and pays attention to the emotions and feelings of his/her subordinates with nun-chi, and reacts to them in a [caring, ] sensitive, empathetic, un-intrusive, and/or gentle manner with jeong
(13) Manager takes/shows an interest in staff as individuals and in their personal lives (4 CCIs)

(14) Manager shows care and concern for the well-being and work life balance of staff (7 CCIs)

(15) Manager listens to the workrelated concerns of staff (8 CCIs)

(16) Manager actively trains or mentors/coaches members of staff (8 CCIs)
(31) A manager provides different types[/styles] of customized feedback according to subordinates' characteristics, competencies, and situations

(32) A manager takes a personal interest in his/her subordinates as individuals (i.e., as human beings with feelings and emotions (jeong)) and shows care for their wellbeing

(33) A manager helps his/her subordinates by providing useful information, advice and/or guidance based on his/her experience and expertise [(e.g., mentoring)]

(41) A manager actively teaches/coaches his/her subordinates and/or adopts a mentoring system with senior/higher ranking employees acting as their mentors

(17) Manager encourages and helps staff with personal development for their present role but also for potential future roles (5 CCIs)

\section{(38) A manager promotes a learning} culture/climate in his/her team

(39) A manager gives subordinates challenging tasks/assignments/projects and/or new opportunities to motivate
P9) Delegates effectively, shares responsibilities as required, and empowers staff to use their own initiative
P10) Listens empathetically and sensitively to the personal concerns, worries, and health/domestic problems of staff, and shows flexibility in the performance expectations placed on them so as to avoid work overload P11) Takes an interest in staff as individuals, listens to their work-related concerns, and shows concern for their wellbeing
P12) Actively trains and mentors/coaches their staff

P13) Encourages and helps staff with their personal self-development 


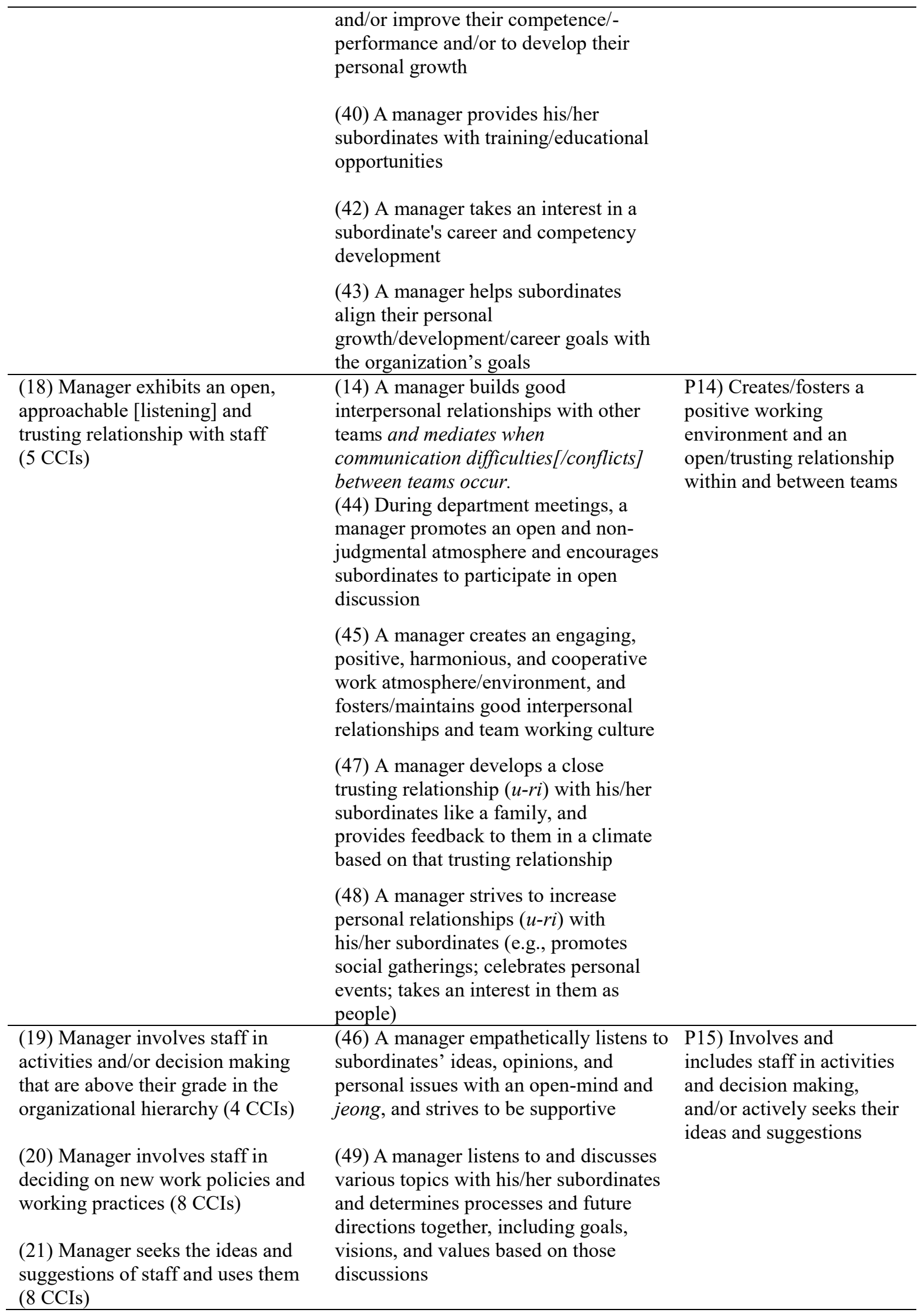


(22) Manager informs and explains decisions regarding changes and/or other issues that will affect staff (5 CCIs)

(23) Manager flexibly assigns/ allocates roles/tasks/workloads in a way that avoids conflict, and takes into account the individual's capabilities/competencies (5 CCIs)

(24) Manager allocates workloads fairly and in a way that minimizes work overload (6 CCIs)

(25) Manager takes care not to overload staff with work, tasks, unnecessary additional work (3 CCIs)

(26) Manager sets clear standards and/or issues good/clear directions, instructions, or explanations regarding assigned roles, responsibilities, and tasks (7 CCIs)

27) Manager addresses/intervenes in, and finds ways of resolving in a fair way conflict that arises between employees (11 CCIs)

(28) When relational misunderstandings or conflicts arise between different departmental staff the manager proactively intervenes to resolve matters (4 CCIs)

(29) Manager provides encouragement to staff to boost their self-esteem and motivation (4 CCIs)
(50) Manager shares with his/her subordinates/team news and key information from top management regarding the company

(9) A manager distributes work assignments to team members fairly and clearly, in order to prevent any complications, such as overlapping, empty work spots, or ambiguity, while fully understanding the whole process of the assignments with expertise and experience

(29) A manager assigns tasks and/or delegates responsibilities based on a subordinate's individual characteristics, strengths, weaknesses, experiences and/or levels of expertise/competence

(10) A manager sets norms, standards, and criteria against which to assess the performance and behavior of his/her employees, and rewards or punishes them accordingly

(51) When assigning a task, a manager explains the context, purpose, scope and processes and expectations, and provides clear goals and directions

(52) When assigning a task, a manager provides his/her subordinate with a clear explanation of their importance, how they have been distributed, and/or the principles, guidelines and boundaries to be observed (14) A manager builds good interpersonal relationships with other teams and mediates when communication difficulties [/conflicts] occur between teams.
P16) Keeps staff informed on change issues

P17) Allocates staff roles, tasks, and workloads clearly and fairly

P18) Sets clear goals/standards and gives staff clear directions instructions, explanations, and guidelines regarding assigned roles and tasks
P19) Proactively resolves interpersonal conflict and/or relational problems between staff/departments
(23) A manager takes action to boost the self-confidence and self-esteem of his/her subordinates (e.g., encouraging with positive feedback; saying things that demonstrate trust in their abilities; encouraging them to attempt higher value-added tasks; reminding them of their valued contributions)

\section{P20) Provides} encouragement to staff to boost their self-esteem, confidence, and motivation 
(30) Manager secures extra

resource or outside help in support

of staff

(4 CCIs)

(31) Manager encourages and/or personally helps members of staff to learn from their mistakes (5

CCIs)

No obvious transparent convergent

meaning/overlap

BSs (5); (20); (24); (25); (26); and (53) 
Table 3 SK public sector derived negative BSs $(n=35)$

1) Manager issues unclear directions/instructions and/or omits to give any at all (8 CCIs)

2) Manager deprives staff of clear explanation and/or guidance of decisions or instructions regarding required revisions to existing work, new tasks, or new working arrangements that place extra demands upon them (7 CCIs)

3) Manager allocates work unevenly, overloading some individuals or departments while under loading others (3 CCIs)

4) When assigning tasks/workload to staff the manager fails to take into consideration the time required or their individual competencies (4 CCIs)

5) Manager burdens staff excessively with work beyond their capacity/capability (5 CCIs)

6) Manger makes [subjective] decisions that leads to wasteful use of resources (5 CCIs)

7) Manager exhibits bad judgment (e.g. misjudging priority issues; relying on inexperienced opinion; issuing impossible to fill orders; and/or over-reacting to situations) (5 CCIs)

8) Manager tolerates or even allows certain members of staff to perform below standard (4 CCIs)

9) Manager shows no respect for staff as individuals, and/or for their sensitivities, values, personal lives, or even entitlements (5 CCIs)

10) Manager ignores the expressed concerns of staff and/or overlooks any signs of them having problems or being in difficulty (3 CCIs)

11) Manager autocratically imposes his/her will on staff without prior consultation and/or giving any explanation (4 CCIs)

12) Manager avoids and/or ignores advice of experts and the opinions of his/her own staff, but instead requires staff to follow his/her decisions/orders based on his/her opinions only (8 CCIs)

13) Manager ignores and/or refuses to listen to the opinions, advice and/or suggestions of staff or colleague managers (5 CCIs)

14) When things go wrong or there is a risk of criticism from higher management or from outside agencies the manager shifts the blame onto staff (4 CCIs)

15) Manager is inconsistent in the work standards expected from staff and how he/she treats them (4 CCIs)

16) Manager shows favoritism to certain members of staff (7 CCIs)

17) Manager exhibits selfish, self-serving, and/or spiteful behavior at the expense of his/her staff and departmental Budget, or colleague managers (8 CCIs)

18) Manager manipulates and/or misuses staff and/or resources to serve their own selfish/self-serving interests (6 CCIs)

19) Manager shouts/yells at and reprimands/scolds staff in public (6 CCIs)

20) Manager criticizes staff in front of others, drawing attention to their weaknesses in ability and expertise or to their mistakes, and/or tells others of their shortcomings (5 CCIs)

21) Manager picks upon certain staff by drawing attention to trivial weaknesses and/or rejecting their work for tiny errors and/or is unforgiving [hostile] about mistakes made by team members (6 CCIs)

22) Manager discriminates against staff on grounds of gender and/or denigrates them through sarcastic or disparaging comments (4 CCIs)

23) Manager procrastinates (delays/puts off) making decisions and taking required action and/or responds to issues only at the last minute ( $8 \mathrm{CCIs})$

24) Manager ignores or fails to take action to prevent/resolve potential/actual problems or conflicts in the department (7 CCIs)

25) Manager offloads/passes responsibility to staff or outsiders for generating ideas for new directions or ways of departmental functioning and/or to address difficult issues (e.g. handling inter-departmental conflict; or challenging the boss regarding the business plan) (6 CCIs)

26) Manager provides no guidance or training to help staff take on assignments, and/or to improve their competence/capability [performance], and/or give them any support and encouragement regarding their personal/professional development (8 CCIs)

27) Manager fails to convey accurately directions and/or information from higher management (3 CCIs)

28) Manager is rigid in his/her thinking and actions and is closed to the thinking of others (3 CCIs)

29) Manager is closed to new ideas, new types of work, or new ways of working and instead remains stuck in the past (5 CCIs)

30) Manager forces or psychologically induces staff to work overtime and/or at weekends at the expense of their 
personal interests/well-being (5 CCIs)

31) Manager exhibits a mistrust of staff by constantly checking up on them, allowing little discretion, and/or micromanaging them (8 CCIs)

32) Manager fails to delegate, holding onto tasks that could be delegated and/or getting involved in [micromanaging] the trivial aspects of delegated tasks (3 CCIs)

33) Manager engages in undermining behaviour (e.g. ignoring the organization's rules, regulations, and/or policies; bypassing organization systems/procedures; ignoring the opinions of subordinate managers and/or bypassing them; and/or infringing on individual freedoms) (7 CCIs)

34) Manager omits to investigate/review or check his/her understanding of proposals or issues before taking action or giving instructions to staff (7 CCIs)

35) Manager resists or avoids taking on new projects, ideas, or unfamiliar tasks for self and/or the department (4 CCIs) 
Table 4 Deduced generic behavioural criteria through cross-case/cross-sector comparative analysis of SK public sector and SK private sector BSs

\section{Deduced Positive SK Generic Behavioural Criteria Underpinning Positive (Effective) GBIs Near Opposite in Meaning Negative (Ineffective) GBIs}

1) Exhibits good judgement and makes well informed decisions based on best evidence and a clear understanding of issues

P1) Develops plans and policies based on best evidence derived from analysis and/or expertise of others, plus a clear understanding of the strategic direction of higher management

P3) Takes the initiative and makes timely decisions in executing plans

N3) Exhibits poor judgment and makes bad decisions

N19) Omits to obtain a clear understanding of an issue or to check their understanding prior to taking action or to giving instructions to staff

2) Good organising and directing including fair allocation of roles, tasks, and workloads, and giving clear instructions

P17) Allocates staff roles, tasks, and workloads clearly and fairly

P18) Sets clear goals/standards and gives staff clear directions instructions, explanations, and guidelines regarding assigned roles and tasks

N11) Manages in an unorganized and inconsistent way

N1) When assigning tasks or revised/-new working arrangements manager gives unclear directions, instructions, or explanations, or fails to provide any

N2) Assigns tasks/responsibilities inappropriately, allocates work unevenly/unfairly, and/or overly burdens staff with workload

\section{3) Seeks new and improved work methods}

P2) Takes action to improve working methods, processes, and productivity

N25) Is rigid/inflexible in applying rules, sticks to established methods, and is closed to new thinking from others

\section{4) Monitors/controls staff performance and resolves problems}

P4) Proactively monitors staff performance and/or progress and provides constructive feedback

P19) Proactively resolves interpersonal conflict and/or relational problems between staff or departments

N4) Fails to check staff performance and/or allows/tolerates poor performance from staff

\section{5) Active supportive management/leadership}

P5) Provides practical help and support to staff/team and/or colleagues when faced with problems or in difficult situations

P6) Gives recognition, praise, credit, and/or reward to staff for their good performance

P7) Provides advice and guidance to staff as and when needed

P8) Resolves or protects subordinates from difficult/stressful situations resulting from top management decisions, problems with other departments, or outsider criticism

P20) Provides encouragement to staff to boost their self-esteem, confidence, and motivation 


\section{6) Delegates effectively \& empowers staff}

P9) Delegates effectively, shares responsibilities as required, and empowers staff to use their own initiative

7) Takes an interest in staff and shows care and concern for their well being

P10) Listens empathetically and sensitively to the personal concerns, worries, and health/domestic problems of staff, and shows flexibility in the performance expectations placed on them so as to avoid work overload

P11) Takes an interest in staff as individuals, listens to their work-related concerns, and shows concern for their well-being

N5) Shows lack of respect [and interest] for staff as individuals, and is insensitive to their concerns, feelings and/or personal rights

N6) Requires/induces staff to work unreasonable amounts of overtime at the expense of their personal lives

\section{8) Develops open and trusting relationship with staff}

P14) Creates/fosters a positive working environment and an open/trusting relationship within and between teams

N8) Exhibits mistrust in staff and/or engages in micro-managing and excessive monitoring

\section{9) Actively provides guidance and training for staff and supports their personal self-} development

P12) Actively trains and mentors/coaches their staff

P13) Encourages and helps staff with their personal self-development

N23) Deprives staff of advice, guidance, or training to help improve their competence and/or encouragement and support for their personal growth/development

10) Open to ideas and thinking of others and involves staff

P15) Involves and includes staff in activities and decision making, and/or actively seeks their ideas and suggestions

N9) Ignores, disregards and/or refuses to listen to the advice of experts and the opinions or suggestions of staff

$\mathrm{N} 25)$ Is rigid/inflexible in applying rules, sticks to established methods, and is closed to new thinking from others

11) Communicates well with staff and keeps them informed on key issues

P16) Keeps staff informed on change issues

N24) Withholds from staff key information

\section{Deduced Negative SK Generic Behavioural Criteria Underpinning Negative (Ineffective) GBIs}

1) Exhibits inappropriate autocratic behaviour

N7) Manages staff in an inappropriate autocratic domineering way

N8) Exhibits mistrust in staff and/or engages in micro-managing and excessive monitoring

2) Exhibits selfish and self-serving behaviour

N10) When things go wrong and/or there is a risk of challenge/criticism from higher management, manager withholds/distorts the facts or shifts the blame onto staff 
N12) Shows favouritism to certain subordinates

N13) Exhibits selfish, self-serving behaviour, and/or engages in politicking, and /or in the manipulation of staff or colleague managers

\section{3) Engages in undermining behaviour}

N14) Criticizes and/or reprimands staff in public

N15) Is unforgiving/hostile to staff when they make mistakes

N16) Engages in discriminatory behaviour towards staff based on gender

N17) Offends and/or denigrates staff through sarcastic. Disparaging, and/or insulting comments

N18) Engages in behaviour that undermines subordinate managers' authority and/or the organization's systems, policies, and procedures

\section{4) Exhibits avoidance behaviour}

N20) Delays/procrastinates in decision making, evades responsibilities, and/or avoids taking action

N21) Avoids attending to essential macro-matters and/or taking on new big ideas/projects

N22) Evades or abdicates from their managerial responsibilities 
Table 5 Deduced emergent SK behavioural taxonomy of perceived managerial and leadership effectiveness

\section{Positive (Effective) Generic Behavioural Criteria}

P1) Exhibits good judgement and makes well informed decisions based on best evidence and a clear understanding of issues

P2) Good organising and directing including fair allocation of roles, tasks and workloads and giving clear instructions

P3) Seeks new and improved work methods

P4) Monitors/controls staff performance and resolves problems

P5) Active supportive management/leadership

P6) Delegates effectively and empowers staff

P7) Takes an interest in staff and shows care and concern for their well being

P8) Develops open and trusting relationship with staff

P9) Actively provides guidance and training for staff and supports their personal self-development

P10) Open to ideas and thinking of others and involves staff

P11) Communicates well with staff and keeps them informed on key issues

Negative (Ineffective) Generic Behavioral Criteria

N1) Exhibits inappropriate autocratic behaviour

N2) Exhibits selfish and self-serving behaviour

N3) Engages in undermining behaviour

N4) Exhibits avoidance behaviour 